\title{
Appraising Adult Second-Language Learners' Subjectivity and Ability in Virtual Worlds
}

\author{
C. A. DeCoursey ${ }^{1}$ \\ ${ }^{1}$ Department of English, Hong Kong Polytechnic University, Hong Kong \\ Correspondence: C. A. DeCoursey, Department of English, Hong Kong Polytechnic University, Hung Hom, \\ Kowloon, Hong Kong. Email: egdecour@polyu.edu.hk
}

Received: September 5, 2013 Accepted: September 20, 2013 Online Published: November 24, 2013

doi:10.5539/ijel.v3n6p44 URL: http://dx.doi.org/10.5539/ijel.v3n6p44

\begin{abstract}
This paper uses Appraisal analysis to explore adult second-language learners' realisations connecting self and ability when using Second Life. In particular, possible selves theory was used to discover whether learners realised a variety of selves. Studies of avatar subjectivity have focused on appearance and bricolage as vehicles for virtual subjectivity. Motivation theory articulates relations between various selves including the here-and-now self and desired selves which may function as self-guides, if a learning task is seen as realistic. In all, 40 student blogs were analysed using computational methods. This study found support for both approaches. Six frequently-occurring positive, and three frequently-occurring negative connections between self and ability are explored through examples. Conclusions are that virtual subjectivity is more goal-oriented and less involved with appearance and game-play in older users, older users accept social limitations on self, and second-language learners' metacritical awareness may impact their ability to understand language tasks as realistic.
\end{abstract}

Keywords: avatars, second-language learning, virtual worlds, possible selves, motivation, second language learning, Appraisal analysis

\section{Introduction}

This paper explores statements about subjectivity and ability among adult second-language learners in a Multi-User Virtual Environment (MUVE), Second Life (SL). Previous research indicated that, while virtual environments facilitate learning through pleasurable activity, adult second-language (L2) learners have little time to spend learning new technologies, and can view themselves as lacking technical ability (DeCoursey, 2012). Language learning theories have recently been re-theorised based in the psychology of the self, in particular the idea that L2 learners imagine a variety of potentially viable selves while learning a language (Dörnyei \& Ushioda, 2009). Possible self theory has articulated how a sense of discrepancy between the here-and-now or "real", and other selves including the ought and the desired, motivate imaginations that assist L2 learners to navigate new tasks. This multiple-selves approach is used here to analyse 40 blogs written by adult second language learners about their experiences in SL. Self has also been crucial in research into learning in virtual worlds. Much research has treated avatar subjectivity, particularly users' engagement with virtual appearance, presence and interactions. MUVEs assume a relation between the avatar as a projected self and the here-and-now person at the keyboard. The person at the keyboard is the L2 learner. Given the increasing use of MUVEs in teaching, and the place of lifelong learning in society, it is important to explore connections between subjectivity and learning in virtual contexts.

\section{Literature Review}

Games using avatars have had a significant cultural presence in Asia since the 1990s (Chan, 2006). MUVEs and avatars are increasingly used for teaching purposes (Johnson, Suriya, Won Yoon, Berret, \& La Fleur, 2002). The feeling of connection between self and avatar facilitates learning (Veletsianos \& Miller, 2008). The virtual self is represented visually by the avatar and textually by synchronous chat (Meadows, 2008). The technical affordances of a highly developed MUVE like SL allow a detailed, customised visual expression of self including such aspects of identity as ethnicity, gender, age, height and many specific facial and body traits, expressions and gestures (DeLucia, Francese, Passero, \& Tortora, 2009). Expression of avatar subjectivity is also mediated by choices made in verbal interactions, which continuously feed back and shape future choices (Bailenson, Beall, Loomis, Blascovich, \& Turk, 2004). These elements of virtual subjectivity predicate a sense of 
personal and social presence (Anetta, Klesath, \& Holmes, 2008). MUVE users treat virtual interactions as they do real social environments (Alvarez-Torres, Mishra, \& Zhao, 2001). They infer personality from visual stereotypes (Yee \& Bailenson, 2009), and interpret verbal interactions using fit-to-context judgments (Veletsianos, 2010). These activities cause users to "strongly identify with" their avatar, which "greatly influences the perceived sensation of presence and awareness" (Andreas, Tsiatsoa, Terzidou, \& Pomportsis, 2010, p. 605). This identification has been called self-presence, the degree to which users "feel as if their avatar on the screen were their real self" (Jin \& Park, 2009, p. 724). Presence feeds back on users' private self-awareness of emotions, values and attitudes, assisting learning (Vasalou, Johnson, \& Pitt, 2007). This study explores $2 \mathrm{~L}$ avatar users' perceived sense of ability in a MUVE context.

Virtual versions of self resemble established understandings of self as multiple (Mansfield, 2000). Avatars offer a performative subjectivity projected through extended sensory abilities and presence, similar to the physical senses used by the here-and-now self (Tofts, 2003). In using these virtually extended abilities, avatars "allow new configurations of self that fulfill wishes and fantasies" (Jones, 2006, p. 12). As MUVEs are increasingly being used in teaching, researchers are interested to detail the links between avatar subjectivity and learning (Chae \& Lee, 2009). MUVEs are used with second language (L2) learners, because avatars facilitate language use (Stevens, 2006) and level social disadvantages (Wallace \& Maryott, 2009). Connections between subjectivity and ability is clearly a factor to consider in this situation. In a MUVE, language is a significant ability that underwrites social presence and interaction. Avatar subjectivity instantiates the communicative choices made by the $\mathrm{L} 2$ learner guiding those interactions.

Research in the psychology of L2 learners formerly distinguished instrumental motivation, the incentive to learn language as a means of achieving professional goals, from intrinsic motivation, a positive attitude towards learning a language as a means of participating in desired L2 cultural products like music and film (Sandrock, 2002). Contemporary L2 learners are motivated by personal interests (Ushioda, 2006). Their L2 identity is dynamic and reconstructive (Yashmina, 2002), involving learners in an ongoing, fluid process of experience, enjoyment, aspiration, contestation, and revision (Holstein \& Gulbrium, 2000). L2 learners recreate their own identities as they respond to the new social realities mediated by language (Crystal, 2003). They are adept at keeping a local identity alongside other imagined participatory social identities (Norton, 2000). At this time, much L2 research uses a "possible selves" or "self-discrepancy" framework (Dörnyei \& Ushioda, 2009).

The self-discrepancy model is well-established in both psychology and linguistics research (Schunk \& Zimmerman, 2007). This model indicates that people imagine a variety of possible selves. The here-and-now self controls pragmatic realia, and is often called the "real" self. The ought self is built from voices accepted as authoritative by the individual. It represents what individuals believe they should be like. For example, the ought self may reflect parents' or teachers' comments that the L2 learner should achieve English proficiency. Desired selves are aspirational, composed of opportunities or dreams wished for, comprising a self the individual would like to become. These might be several, for example "an excellent tennis player", "successful in a business career," "a popular girl with good friends", and "a good English speaker". This self is closer to people's chosen view of themselves, where the ought self reflects accepted social, family or others' expectations (Higgins, 1998).

When people's ought and ideal selves do not resemble their here-and-now selves, they feel an uncomfortable sense of discrepancy, and want to reduce this feeling (Dörnyei, 2005). Possible selves are imagined selves people might become. These combine elements of ought and desired selves, and can function as "self-guides" if they help people make decisions that reduce the sense of discrepancy and move towards greater integration of selves (Cziser \& Dörnyei, 2005). This is viable under two conditions: (1) the possible self is visually-detailed when being imagined, and (2) the immediate tasks set for the here-and-now self to move towards greater integration are realistically achievable. Integration occurs when successful efforts made by self guides become an active part of the real, or here-and-now self (Hoyle \& Sherrill, 2006). L2 learners are especially adept at imagining possible selves, due to the extensive use of improvisation and roleplay in L2 education (Boyatzis \& Akrivou, 2006). For immediate tasks to feel realistic, L2 learners must feel they can control the performance of the imagined behaviour (Dörnyei \& Clement, 2001). Semantically, L2 learners choose the words they use to express themselves, and represent possible selves the same way as the here-and-now self, allowing researchers to observe L2 learners' thoughts and feelings through their speech and writing (Ruvolo \& Markus, 1992). Studies of MUVEs have recently begun to use Higgins' model to explore avatar subjectivity (Jin, 2009). The technical affordances of SL enable the visually-detailed imagination of possible selves, and offer teachers opportunities to set a variety of realistic tasks.

This study explores how L2 learners realise their sense of ability in the process of generating and trialing possible selves. L2 ability may be anticipated as a ground on which discrepancy is sensed, and also involved in 
processes of reducing discrepancy. Many studies of MUVEs locate avatar subjectivity on the boundary between real and virtual, making invention and interaction constitutive of the virtual self (Horrocks, 2003). This suggested that student writing would, to some degree, reflect students' processes of imagination of possible selves. MUVE research has described the "avatar-communicator couple" as "not stable and unitary, but dynamic and multiple" (Schultze \& Leahy, 2009, p. 3), cycling bricoleur-like through a variety of relations. Adult learners make an appropriate group to study this in, as they are notable for self-reflection (Garrison, Anderson, \& Archer, 2000), and for connecting new knowledge to self (Cercone, 2003). They select material they view as significant, integrating this with their experience and current life (Majeski \& Stover, 2007). In English, the expression of abillity is linked to the imagination of skills acquired and potentialities likely to be instantiated in action. Linguistic analysis points to philosophical dimensions entailed in expressing the modality of possibility. English expressions such as "I am able to" connect the person to existential states characterised by potentialities and aspirations. "Can" is not used epistemically in English, but realises belief about future states of affairs based on past experience and evidence, for example, "I can chat to other avatars in English" (Stack, 2012). Such expressions are forms of metonymy, using potentiality to express actual action. The pragmatic meanings of such phrases vary in terms of the strength of their illocutionary force. For example, "I can change my avatar's appearance if I like" has a weak force, indicating something done occasionally as a choice, where "Mum says I have the ability to pass the English test" carries the force of, "I had better pass the English test." Expressions of ability point to conditions existing outside a speaker or writer, including past motivations, acquired capabilities and future potentialities. When these cases connect to a real situation, the statement of non-real potentialities is used to stand in systematically for realities. For example, "I am doing so well with my studying this week, I know I can pass the test" is a potentiality-for-actuality form of metonymy. In English, such statements reflect a process of imagination of the act, which renders the specific pragmatic effect of actuality, and "strongly implies" that the writer is "actually in a state of understanding" (Panther \& Thornburg, 1999, p. 341). Statements of acquired ability, such as "I can be more confident about meeting new people who are native speakers" refers to specific skills that are acquired and have a real use which is exercised on specific occasions. In this case, the implicature is strong, but limited to specific occasions, with the force of meaning that, as one has the ability to do such things, one will do them on those occasions.

Research questions that guided this paper included the following. How do adult L2 learners connect realisations of ability, imagination, and self? How do they realise subjectivity in relation to SL? Does SL involve them in imagining possible selves? Can we see various selves in action, such as the here-and-now, desired and ought self? How does the specific ability of language learning fit into this? What discrepancies do students report feeling? Does SL enable self-guides?

\section{Method}

This study used Appraisal analysis to analyse adult Hong Kong L2 students' blogs about their experience of SL, focusing on subjectivity and ability. Participants were 40 Chinese L2 learners who were graduate students in a course on popular culture. Of these, 30 (75\%) were Cantonese- and 10 (25\%) Putonghua-speakers. All were proficient in English, having attained either IELTS 6.5 or TOEFL 590 (243 computer). All had previously attained an undergraduate degree good enough for admission to a postgraduate MA. All were working either part or full-time as well as attending classes part-time. 31 (77.5\%) were in-service or intended teachers, $9(22.5 \%)$ worked in business or government, as language teachers. Participants' previous exposure to web-based interactive media was small: only one $(2.5 \%)$ had heard of SL prior to this course. Three (7.5\%) reporting prior experience of massively multi-player online roleplay games (MMORPGs) were excluded from the data set, five $(12.5 \%)$ who reported supervising schoolchildren playing online games were not. None had ever previously created an avatar. The median age of participants was 34 years.

Over the initial two week period, participants received one hour of in-lab SL instruction and one hour of in-lab guided exploration focused on SL activities and places. They were then required to spend an unsupervised hour per week in SL for 10 consecutive weeks. Materials itemising various sites and activities were provided in order to help participants familiarise themselves with SL, though these were optional. It was anticipated that adults learners might feel uncomfortable in a MUVE, but posts to the course intranet during the 10 -week period suggested participants were invested in the task, with each writing an average of 1.37 posts per week about SL, and each post receiving an average of 1.81 replies. After spending 12 hours in SL over 12 weeks, participants wrote a 500-word blog. Blogs elicit more subjective content than other tertiary written genres (Herring, Scheidt, Wright, \& Bonus, 2005). The blog was graded for $10 \%$ of the final grade, large enough to create incentive, but not enough to elicit opinions intended to please in order to gain a better grade. The task was clearly stated and communicated (Morrison, 1996). The blog prompt was simple, and did not use lexis which would tend to 
pre-determine topics and opinions realised (Connor-Greene, 2000): "Write 500 words about your experiences in Second Life". This allowed participants to realise subjectivity and ability in ways that represented their own perspectives. Data was taken from the 40 blogs. Electronic submissions were assembled into a corpus of 25,396 words. These were uploaded to the CorpusTool software (O'Donnell, 2008).

Realisations of the modality of possiblity and related expressions for ability were tagged, including "can", "able", "ability", "have the ability to" "know how to", "capable of", "got the capability to", "am skilled at", "have the expertise to", "proficient at", "competent in", "have the aptitude to", "got the knack of", "have a flair for" and "X enough" where $\mathrm{X}$ is an adjective indicating ability. Realisations were then checked for their connections to various selves. Instances were excluded where the mention of ability did not connect to self, for example, "Suddenly I discover my avatar friend can fly" (ability connected to another self) or "Second Life offers many amazing abilities and places" (ability attributed to SL). The remaining realisations were analysed using Appraisal analysis (Martin \& Rose, 2003). Frequently occurring connections between positive and negative ability and self were identified. Examples were selected to demonstrate frequent categories of comment.

Appraisal analysis uses the Attitude system networks developed in systemic functional linguistics (Halliday, 1994). These focus on taxonomising subjectivity in spoken and written texts (Marín-Arrese, 2004). When expressing opinions, people make specific lexicogrammatical choices to represent their views (Martin \& White 2005). These choices may be classified using the Appraisal System networks, which are broken down into categories and subcategories of increasing delicacy (Hunston \& Thompson, 2001). The use of Appraisal networks for sentiment analysis is well established within both psychology and linguistics (Argamon, Bloom, Esuil, \& Sebastiani, 2007). Text-tagging software programmes are routinely used for such analyses (Polanyi \& Zaenen, 2006). This method is viewed as reliable (Subassic \& Huettner, 2001; Taboada, Brooke, Tofiloski, Voll, $\&$ Stede, 2011). The combination of machine-tagging with checking by trained human taggers is robust (Bruce \& Wiebe 1999; Whitelaw, Garg, \& Argamon, 2005). Attitudes realised are either positive or negative (Wiebe, Wilson, Bruce, Bell, \& Martin, 2004). Polarity may be calibrated through graduation, for example by using "really", "not very", "a lot", "none" and so on (Scherer, Schorr, \& Johnstone, 2001). Both more and less direct forms of expression are possible in the English language. The realisation 'I can" is congruent, directly reflecting a reality experienced. Congruent realizations "bear a natural relation to the meanings they have evolved to express" (Halliday, 1985, p. xviii). Lexicalised realisations are less direct, for example "I have the capability to", where capability has become a noun, a grammatical metaphor (Bloor \& Bloor, 2004). When a person chooses to express themselves in a lexicalised way, we can say that the connection has been placed at a greater distance from self (Thompson, 2004). Both polarity and lexicalisation may be represented on a cline (Wiebe, Wilson, \& Cardie, 2005).

\section{Data}

Electronic submissions were assembled into a corpus of 25396 words. The corpus contained 704 realisations of ability in total. Of these, 92 connected ability to SL, 69 connected ability to other avatars and were excluded from the data set. 543 connected ability to the virtual self. Attitudinal density was 27.72 per 1000 words. Mean attitudes realised about ability was 17.60 per blog. Most realisations of ability $(467=86.00 \%)$ were positive, 76 $(14.00 \%)$ negative. Most $(423=77.90 \%)$ were positive and congruent, that is, "I can". Some were positive and slightly lexicalised, taking the form of "I am able to/capable of/skilled at/proficient at/competent in". Few were more-lexicalised in "I am X enough to", "I know how to" and "I have the ability to/have the aptitude for/got the capability to/got the knack of/got the flair to/have the expertise to". Of negative realisations, some were negative and congruent ("I can not", 59=10.87\%). Few were slightly or more lexicalised, as in Table 1. 
Table 1. Positive and negative, congruent and lexicalised participant realisations of ability

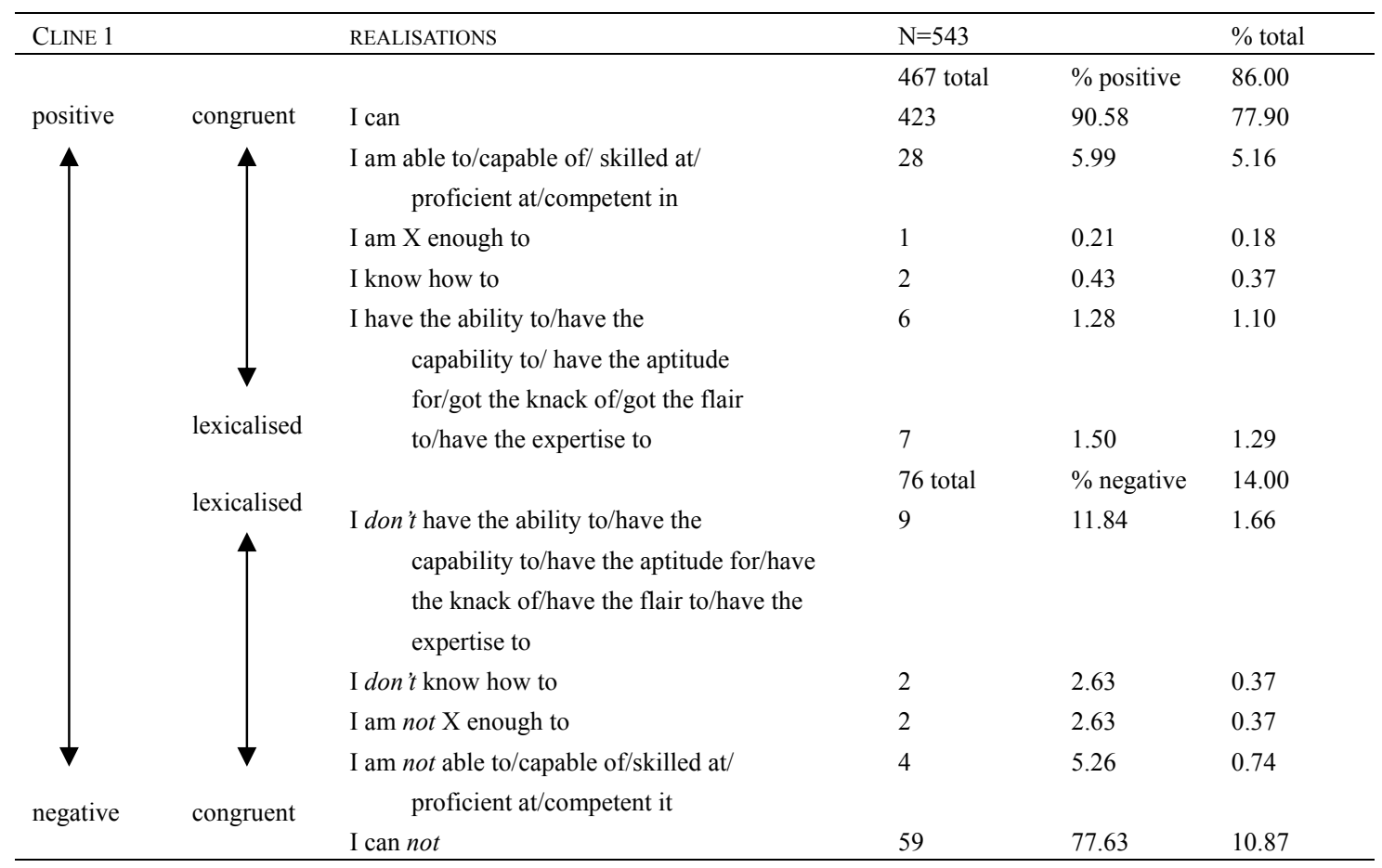

So most of the time $(482=88.77 \%)$, students directly realised a personal experience.

Mean realisations of ability regarding self per blog was 13.55 . Most $(51=67.11 \%)$ of the 76 negative realisations were concentrated in $13=32.50 \%$ of blogs, which also included $268=57.39$ of positive realisations. So positive and negative expressions of ability were often expressed together. Frequently-occurring connections between ability and self are seen in Table 2 .

Table 2. Frequently-realised positive and negative connections between self and ability

\begin{tabular}{llll}
\hline & Frequently-realised connections & N & \% \\
\hline & POSITIVE ABILITY & & \\
1 & and the 2L self & 29 & $\mathbf{7 2 . 5}$ \\
2 & able desired selves as self-guides & 24 & $\mathbf{6 0 . 0}$ \\
3 & and negative ability together & 19 & $\mathbf{4 7 . 5}$ \\
4 & and ambivalence about possible self & 17 & $\mathbf{4 2 . 5}$ \\
5 & and imagined professional self & 17 & $\mathbf{4 2 . 5}$ \\
6 & and appearance & 12 & $\mathbf{3 0 . 0}$ \\
& & & \\
& NEGATIVE ABILITY & & \\
1 & and paralanguage & 9 & $\mathbf{2 2 . 5}$ \\
2 & dramatising other realities & 9 & $\mathbf{2 2 . 5}$ \\
3 & and the L2 self & 7 & $\mathbf{1 7 . 5}$ \\
\hline
\end{tabular}

\section{Discussion}

On the one hand, comment on $2 \mathrm{~L}$ ability was anticipated as participants were language teachers registered in a subject about using popular culture to teach English. On the other hand, as the prompt did not elicit comment on ability, the mean realisations of ability, 17.60 per blog, suggests this was a significant aspect of students' 
experience of SL. The combination of positive and negative expressions together is a feature of Confucian rhetorical style (Panetta, 2001). As Chinese culture avoids direct criticism, preferring an indirect style employing hedges, multiple terms, and a mix of positive and negative terms together (Wei \& Lei, 2011), the strong positive results support the view that $2 \mathrm{~L}$ learners positively evaluated $2 \mathrm{~L}$ as enabling. Realisations connected ability to self much more frequently than to SL or to other avatars, as seen in the mean, 13.55, for such instances. As most realisations, whether positive or negative, were congruent, suggests learners reported their sense of a direct experience of ability rather than an experience they chose to place at a distance from self. Students mainly expressed a congruent connection between ability and self, that is, "I can". The choice "I can" was not merely a convenient grammatical expression, as blogs were written by proficient English speakers who would not need to rely on the easiest choice, Chinese students would tend not to do so, graduate students are accustomed to expressing complex ideas, there was ample time to prepare this blog, and the blog was graded which would tend to sophisticate their language. These circumstances would favour lexicalised over congruent choices (Malvern, Richards, Chipere, \& Durám, 2004). So, the preference for congruent expression clearly suggests a choice to directly and naturally represent their experience of virtual subjectivity.

We can explore what these congruent choices show about ability, self and learning, through examples of the frequently-realised connections of ability and self.

\subsection{Ability and the L2 Self}

Most $(29=72.5 \%)$ blogs connected self to L2 ability. In example A, the student evaluates her SL language learning positively.

A 1. In my Second Life experiences, I find that I can learn a language freely without any pressure. 2. I can learn it in any time and any situation. 3. First, in a different environment, I can communicate with different people. 4. Since we do not know who they are, I am not scared to express my feeling, thinking. 5. I can use my language freely. 6. Second, since I feel interested in this experience, I am willing to talk more. 7. It gives me more chance. 8. I become self-confidence to express my opinions. 9. Self confidence is very important. 10. With self confidence, we can act more naturally and easily.

The ability of the here-and-now self "I" (sentence 1) is presented as a positive behavioral surge, "I find I can", occurring against a background normal state, "pressure". The repeated mentions of difficulties encountered elsewhere by the L2 self indicate the discrepancy felt by the here-and-now self in daily life but not felt in the MUVE; "pressure" (2), "scared" (4), not using English "freely" (twice in 1, 5), not having "self-confidence" (three times in 8, 9, 10). The extension of "can" in "learn" (twice in 1,2), "communicate" (3), "use" extended by "my language" (5), and "act" (10) clearly focus on language learning and use. Here, "I" is the L2 self, coordinating the relationship between the here-and-now and desired selves, focused on language. This example shows the virtual desired self functioning as self-guide, helping the here-and-now student reduce discrepancy.

\subsection{Able Desired Selves Acting as Self-Guides}

Many blogs (24 or 60\%) saw the desired self as able, and noted its positive impact on the here-and-now self.

B 1. I like the sensations that the other side of my personality can make when I was an avatar. 2. I became skilled to do so many things.

C My avatar can speak on my behalf to express my genuine self to my congenial avatar friends.

D This experience helped me to learn that I can do more than I think I am capable of.

In example B, the here-and-now self "I" positively evaluates a desired self ("other side"), congruent in "can" and extended by "make" (1) and "became skilled to" (2). The sociable avatar as a desired self is able ("can" extended by "speak", "skilled" extended by "do"), enacting abilities the here-and-now self feels it does not have. In B and $\mathrm{C}$, the possible self creates optimism sufficient for gaining new experiences, which may in time lead to competence. Thus, these desired selves have functioned as self-guides. In D, we see the moment where this has occurred, and the student realises it. "Me", "I" and "I" are the newly advanced here-and-now self reporting an increased ability level, the "can do more" created by the virtual desired selves" experiences in SL. The last "I" is the earlier here-and-now self prior to 12 weeks of SL, a self less "capable" than the current here-and-now self. The distance between the new and the past here-and-now selves is visible in the lexical distance chosen in "capable" for the past version, compared to the congruent, direct experience of "can" chosen for the current one.

\subsection{Positive and Negative Ability Together}

Congruent expressions of positive and negative ability were often found together. Many blogs $(19=47.5 \%)$ represented the here-and-now self as both able and not able, in contrast to the avatar as an able but unrealistic 
possible self, as seen in example E.

E 1. Second Life gives me a chance to act in the way I will not, must not, or cannot act in real life. 2. Therefore the range of activity in Second Life that I can do is far wider than in real life, while I can change whenever I want to. 3 . This change is very valuable because everyday we have to follow routines and rules in the real life. 4. For example, in my chat log there are many sentences that I must not say to someone in reality. 5. I cannot ask someone to marry me who has just known me for 20 minutes. 6 . I will not say that I study architectural engineering.

Here, the avatar is a possible self ("me" sentence 1), contrasted with the here-and-now self realised as negatively able and amplified by "will not, must not, or cannot" (1). The negative ability of the here-and-now self is extended in a range of processes: "act" (1), "say" (twice in 4, 6), and "ask" (5). By contrast the avatar as possible self is able, "can" extended by "do" (2), positively evaluated as "valuable" and intensified by "very" (3). Despite acknowledging its inability, the here-and-now self remains in charge of the avatar. Six uses of "I" express the here-and-now self, whose inability is complex. Some inabilities are chosen, for example "will not" (twice in 1, 6), others imposed ("cannot" twice in 1,5). Even when escaping these inabilities, the here-and-now self directs the desired self - "I can" extended by "change", and "I want" (2) which prompts the here-and-now self's adjudication of the avatar as "very valuable" but unrealistic. This possible self may not act as a self guide. Instead, the here-and-now self, accepting inabilities as realistic, plays out a fantasy desired self in a self-aware manner, controlling imagination of and relations between selves for pleasure and interest. The idea used to manage all of this is ability, both positive and negative.

About half of participants expressed the here-and-now self as both positively and negatively able, as in example E. As MUVEs facilitate bricolage, we may wonder whether SL will facilitate the imagination of many possible selves, but tend to ignore discrepancies arising. In E, discrepancy is not ignored. It is noted as a negative ability but accepted. In place of reducing the discomfort of discrepancy, a logic of contexts and selves connects different abilities with different places, obligations and opportunities. In real life, action "cannot" be taken to reduce discrepancy, and "routines and rules" "must" be followed. The here-and-now self explicitly compares real and virtual worlds, selves and abilities, managing these coherently-selves and worlds are not confused. The writer is capable of expressing the desired self's point of view, as in sentence 2, related cohesively to sentence 1 in "Therefore". The next sentence moves from L2 and desired to real life, expressing the here-and-now self's views. The writer calls this a "change" (twice). It is adjudicated as "very valuable", an expression which can only belong to the here-and-now self. The writer chooses congruent expressions of ability, indicating the experience is being represented directly, rather than indirectly or set at a distance from self. Overall, this suggests the adult here-and-now self remains in charge of managing various selves in virtual environments.

Further support for this is found in the fact that relatively few ( 8 or $20 \%$ ) students expressed the avatar as a possible self without explicitly referencing the here-and-now self. This creates difficulty in determining whether the learner views the avatar, or possible self, as realistic. For example:

F 1. We can immerse ourself in a comfort zone. 2. We are capable to do this.

G You can feel free to do many things whenever you want, even you can fly, you can express your anger by stepping [stamping] on the floor.

In F, a comparison with the here-and-now self's reality is implicit ("we can" in 1, "We are capable" in 2) and the suggestion that comfortableness is not the norm. A similar comparison is inferred in G, where "you" (4 times) stands in for a desired self. But the lack of explicit reference to the here-and-now self prevents us from seeing whether this ability is assessed as realistic and possibly a self guide, or remains a fantasy ability of a desired self.

\subsection{Ambivalence about Possible Self}

Many blogs $(17=42.5 \%)$ expressed ambivalence about possible selves' abilities:

$\mathrm{H}$ 1. I am a girl who is shy and introverted. 2. How can I behave like a frisky woman? 3. I want to go dating but I cannot be a modern girl who is rude or uncivilized.

$\mathrm{J}$ 1. As the dominators of our avatars, we play according to the virtual world disciplines. 2. Also, these characters bring us back to the freedom feelings of affective intuition which we might never assume in real life. 3. For instance, we can indeed decide to become another gender's member, which is totally beyond imagination in real lives.

In $\mathrm{H}$, discrepancy is felt between the inhibited here-and-now self and desired virtual self with the ability to date. Discrepancy is realised as a doubted or negative ability ("How can I" 2, "I can not" 3). The ability of the 
imagined desired self is questioned where the inability of the here-and-now self is asserted. The ought self is evoked through the negative or limited abilities of the here-and-now self controlling the avatar. All uses of "I" realise the here-and-now self. The desired self does not create confidence and optimism even though the task is realistic, and so does not become a self-guide. In this case, the here-and-now self's appraisal of positive and negative abilities is based on social rules, with negative ability realising a rejection of these abilities. We see that realisations of virtual ability could aid teachers as a diagnostic process, as learners use them to signal personal limits in tasks undertaken.

In J, the here-and-now self ("we" 1 ) identifies a desired self as a past version of the here-and-now self ("bring us back to" 2). The "freedom feelings of affective intuition" are memories belonging to the here-and-now self, who has generated the emotionally-free desired self. This implies freedom of emotion causes discrepancy for the here-and-now dominator self, who cannot allow himself such freedom. The attribution of ability ("we can indeed" 3 ) connects the here-and-now self to a virtual transgender self, a second desired self. The here-and-now self and the two desired selves are linked in a complex expression of a self-aware, multiple, and carefully orchestrated subjectivity. But the imagined desired self, though able, does not act as a self guide. In $\mathrm{H}$ and $\mathrm{J}$, the here-and-now self manages a fundamental category of identity, sexuality, via a virtual desired self. Ability and disability are present together. While both participants generated desired selves, neither viewed the challenge as realistic. It is to be expected, that learners generate desired, past or forbidden virtual selves, this may create pressure to resolve the discrepancy, and that 12 weeks of SL may not be sufficient time for socially transgressive desired selves to become self-guides. Also, it is likely that discussion of personal matters was limited in graded assessments. Data in this study may under-represent the potential impact on learners, but we see the transformative potential of SL.

\subsection{Imagining the Professional Self}

Many (17=42.5\%) imagined a professional self, as a form of desired self.

$\mathrm{K}$ 1. There are huge differences from real life. 2. The reason of high popularity of virtual platform is that people will feel more comfortable. 3. You can do tons of things that you cannot in your real life. 4. The dreams you always seek for can also come true in Second Life. 5. People can be more comfortable of new ways of thinking about relationships and even power. 6 . For instance, a person who works as a servant but would love to become a manager, he can perform and achieve it in Second Life.

L 1. It is wonderful and unforgettable experiences for me to participate in Second Life. 2. In my point of view, I can play different roles that I cannot in my daily life. 3 . These activities allow lots of participation, interaction and socialization. 4. It changes my behaviour, ideas and language. 5. In SL when I have assumed a new identity, I tried out being a business man. 6 . I did bluff sometimes and the people reacted to what I had said. 7. I used language to bargain with the others. 8. When they were going to leave at the moment so they wanted to finish quickly, I used a proper excuse for that context. 9. The most important thing that I have found out in SL is that people can change greatly according to different situations. 10. I come to realize that I can change and I may have changed a lot because of the immersion in so many different roles. 11. In my opinion, I was quite serious and it is just my personality. 12. Now I know it can be improved.

In $\mathrm{K}, 1$ and 2 are hypotactic, and can be restated as: "SL is popular because it makes people more comfortable than they are in real life". This indicates discrepancy felt by "people", an indefinite version of the here-and-now self. In 3 "you" is the desired self whose ability "can" extended by "do" amplified by "tons of", and restated in 4 and 5, "can" extended by "also come true", and "can" extended by "be more comfortable". This ability is described as shared with SL. This student is comfortable with the dreamed-of, desired self, "manager", only as far as thinking about it. He does not yet view it as realistic, calling the difference between real and SL as "huge". The here-and-now "person" uses SL to explore a desired self which seems difficult to control or perform. The here-and-now self's feeling like a "servant" suggests the degree of discrepancy and size of the task. The "servant" has an ability when trying out the desired manager self, "can" extended in "perform" and "achieve", but this functions as a guide only in a limited way, as the desired self remains a dream. So here, we see the initial stages of the formation of a self guide.

In $\mathrm{L}$, the writer moves between an uncertain here-and-now self and an able desired self. The relationship is unstable, showing a flexible substitution between here-and-now and desired selves, and revealing the process of a desired self acting as a self-guide. To begin with, the here-and-now self positively evaluates its ability to "play different roles" (twice 2),or imagine possible selves with more abilities than the discrepant here-and-now self can in "daily life" ("can" extended by "play", "change" twice, and "be improved"). Trialing the ability is expanded 
in the story of roleplaying a possible professional self, where the task is difficult ("bluff"), but attainable in the oral genres of bargaining and leave-taking (7-8). The story justifies the claim in 3-4, that roleplay allows participation leading to desired changes, in "behaviour, ideas and language". A task has been competently performed, and discrepancy successfully reduced. A summation is offered in 9-12, where the "most important" finding is that "people can change", expanded in "I can change", extended in "I may have changed a lot", and evaluated positively as "my personality ... can be improved". Here, imagination of a professional self in SL has functioned as a self-guide.

\subsection{Positive Ability and Appearance}

MUVE research indicates appearance as an important vehicle for expressing subjectivity. Some blogs $(12=30 \%)$ connected appearance with ability and self.

M 1. The appearance of the avatar can be changed anytime according to what impression I want to make on the participants. 2. Because I want to be the most beautiful vampire in SL. 3. I easily got the knack of putting on the right dresses.

$\mathrm{N}$ 1. I can design my own appearance, beautiful or ugly, female or male, animal or half-animal- half-human.

2. Even you are a heavy girl in real life, and you can change into a sexy girl to experience the sweet of dating and admiration. 3. You can crazily shop for the luxury items which you always stop and look at through the window in your real life. 4. If you are a poor young man freshly graduate from the university, you can design your dream house and a expensive car parking in your garden. 5. If you are a teenager, in Second Life, you are like a bird flying to the place where you always fantasy.

In M, ability is attributed to the avatar's appearance as an aspect of a desired self. But as this took place in a vampire's dungeon, the here-and-now self, aware of the game-like quality of the situation, did not view it as a potential self-guide. Game selves were unusual among these participants. Only $5=12.5 \%$ wrote about game interactions. In all cases, appearance connected to an ability to make impressions on other players. This suggests that, for adult learners, game selves may not effectively reduce discrepancies, as game selves are not taken seriously as self-guides.

$\mathrm{N}$ begins with an expression of ability, "I can", extended by "design" (1). The indefinite use of the personal pronoun "you" (2) signals a narrowing of focus onto the design ability at the same time as an expansion of that ability in application to all avatars. This is expanded in three clauses where appearance indexes potentialities of the avatar as desired self ("beautiful or ugly, female or male, animal or half-animal-half-human") . It is further expanded in four examples where virtual ability connects a desired with the here-and-now self. One cannot tell which represents the writer's reality or desired self; the "heavy" girl become "sexy", the window shopper turned consumer, the fresh grad dreaming of a designer lifestyle, or the teenager fantasising about freedom. The use of "even" (2) "crazily" (3), and "if" (twice, 4 and 5) shows this learner appreciating the potential of the MUVE affordances. This adult learner's cycling through appearances only superficially resembles bricolage, and does not generate a self-guide. Instead of trying out appearances as possible social and interactional moves, this teacher, like ourselves, reflects on the power of MUVE abilities to change identity.

Most blogs did not notice appearance. Those that did were game-playing or reflecting. None connected the ability to alter appearance to a realistic desired self able to become a self guide. Appearance as a major vehicle for self in MUVEs may reflect younger learners' concerns. As adult learners select material they view as significant and are marked by reflection about these topics, this is an area requiring greater research into MUVE subjectivity.

\subsection{Negative Ability and Paralanguage}

Some blogs $(9=22.5 \%)$ linked language inability to SL's technical affordances:

$\mathrm{P}$ 1. I did encounter some technical problems. 2. I can not use the tone of my voice. 3. You are not able to use tone or gestures. I don't know how to make myself wave.

Q I can not make much use of body language to express friendliness as there were only limited choices of default gestures available.

$\mathrm{R}$ 1. The expressions in Second Life are standardized, which is a big contradiction. 2. We can see so many avatars laughed in exactly the same way! In addition, the interactions among avatars cannot be compared with that of actual life. 3. When my avatar wanted to kiss with the other avatar...

L2 students appreciate the communicative importance of paralanguage. P and Q express the proficient L2 self's sense of discrepancy created by technical affordances that do not meet their needs for visually-detailed 
imagination of a desired self. In R, negative and positive abilities are expressed together. Ability is the ground on which the here-and-now self appraises SL as unable to offer sensorily-detailed imaginations of a desired self. The "big contradiction" indicates a discrepancy felt. Inability is explicitly compared the here-and-now self in the superior position because of an ability it has and the virtual possible self, does not.

\subsection{Negative Ability Dramatising Other Realities}

Some blogs $(9=22.5 \%)$ positively evaluation of an inability, dramatising another reality.

$\mathrm{S} \quad 1$. I just can not stop to continue exploring the places I have been to.

$\mathrm{T}$ 1. My natural feelings and empathy for the character X apparently flooded. 2. I was terribly hurt although I was aware that it was just in a virtual world and $\mathrm{M}$ is only my avatar. 3. It seems that I have assumed her point of view at that moment. 4. Until now, I cannot forget that experience. 5. I think the reason is that I was in $\mathrm{M}$ and she was also in me.

$\mathrm{V}$ 1. It is really easy to become the first speaker in Second Life, because you know you cannot bare [sic] any responsibility. 2. You can just leave the place or change to other maps once you feel uncomfortable.

In S, inability is a process, "can not" extended in "stop", "continue" and "exploring". This is meant as ironic, in fact expressing ability, dramatising the here-and-now self's positive experience. This participant is happy being caught in this ongoing able state. In T, the here-and-now self's emotional investment in another avatar, X, confirms that imagined selves are experienced as having a reality similar to the here-and-now self. The here-and-now participant and desired-self avatar are more equivalent that the grading down, "just", "only" (2), suggests, as seen the moment when the here-and-now self realises its assumption of the possible self"s "point of view" (3) and both being "in" (5) the other. An implied positive evaluation of a negative ability, "I can not" extended in "forget", indicates the value of this possible-self experience to the here-and-now self.

In V, the here-and-now self's inability is a consequence of the desired self's ability, and evaluated positively. The negative ability, "cannot" extended in "bare [sic] any responsibility" is matched by the positive ability, "can" extended by "leave" and "change", all of which facilitate becoming "first speaker". The avatar is a desired self, characterised especially as "first speaker", because it is freed from constraints suffered by the here-and-now self. The desired self enables the controlled performance of a task realistic in SL but not in daily life. The here-and-now self's feelings of competence and optimism are implied through antonymy in the rejected feelings of discomfort and responsibility.

\subsection{Negative Ability and the L2 Self}

A few blogs $(7=17.5 \%)$ connected negative ability and the L2 self. Five stated an interest in Japanese culture, and visits to Japan in SL, where they received messages they could not respond to.

W 1. I am able to look Japanese. 2. But they know when I can't speak Japanese.

$\mathrm{X}$ 1. In Second Life I am Japanese but my appearance is not genuine and can't be the truth. 2. More, I can be a boss in this virtual life, but in fact I am a Primary school teacher. 3. Similarly, the appearance and the background of the players I meet were also not believable.

Here, the not-able desired self feeds back on the here-and-now self, creating discrepancy. Virtual ability is seen as false, contrasted with here-and-now "truth". Being proficient in English may make a detailed imagination of Japanese proficiency seem an unrealistic task, and so, SL and other avatars are discredited. The process of imagining desired selves serves to dramatise the here-and-now self's negative ability. Having an ordinary job provides a co-ordinated measure of inability, making SL appear a fantasy playground without use or purpose. This imagination did not function as a self-guide, and did not help the student respond to new input, make choices, become what is desired and avoid what is feared. The sense of discrepancy was too strong, due to past language learning experiences, and so disconfirmed the imagined possible selves ("not believable" 3, "can't be the truth" 1).

\section{Conclusion}

MUVE research indicates that richly detailed virtual environments like L2 facilitate multiple subjectivities. Research in $2 \mathrm{~L}$ selves indicates that richly imagined subjectivities assist learners in moving towards their desired L2 self, via realistic tasks. Data from these 40 participants is consonant with these two prior research paradigms, but can nuance that previous work. $2 \mathrm{~L}$ adult participants in SL see ability as a significant aspect of virtual self. Many texts represented the here-and-now self as agentic, being in charge of relations between selves, and actions undertaken by selves. They experience discrepancy in SL, and want to reduce it. They imagine multiple selves, including a variety of desired selves which can function as self-guides and possible professional and L2 selves. 
They can feel discrepancy but accept some socially-defined limits, for example in the matter of sexualities. They seem not to experience discrepancy in gaming situations. Participant blogs allowed us to see the processes of desired selves functioning as self-guides, in the process of becoming internalised, as tasks were competently performed and discrepancy reduced. Realisations of ability were mainly congruent, expressing a direct connection between the self and the experience of being in SL. Blogs showed us how adult participants realised a mix of positive and negative evaluations together, especially when focused on their language abilities, and on SL's support for paralanguage. But bricolage was not characteristic of these adult learners' subjectivity, so much as complexity was. This may be because adult learners invest in avatar appearance and as a vehicle for exploring subjectivity and intersubjectivity, and are therefore disappointed when they reach the limits of the MUVE affordances. Their comments are marked by a greater reflectiveness, both positive and negative, about MUVE affordances. It seems that for adult learners, this awareness acts its own motivating, and at times demotivating, factor. Overall, these adult learners tended to articulate complex constellations of selves, connected to statements of complex negative and positive abilities. In some cases, this can identify issues that language educators might use as a diagnostic tool for assessing when and how students view specific tasks as unrealistic, despite the good functioning of visually-rich imagination.

We can draw three main conclusions from this data. First, multiple subjectivity varies with age, and may be more goal-focused in adult learners, and at the same time reflect social norms. Second, adult MUVE users may not take as much interest in appearance and game-like interactions, and may be more impacted by affordances which are not currently available such as paralanguage. Research indicating that older players feel less identification with avatars (Blinka, 2008) may in fact disguise more sophisticated relations with the interface. Third, L2 learners may use MUVEs in ways that specifically reflect their greater metacritical awareness of literacy (Ruddell \& Unrau, 2004), which suggests that the very MUVE technical affordances that facilitate L2 work can make other language-related tasks appear unnecessarily unrealistic. This study has limitations. The data set was small. Given the utility of MUVEs for L2 learning and in-service teacher training, there is a need for more research in this area. In particular, studies are needed which explore the role of visual detail in subjectivity and language learning, using both MUVE and motivation research. For language educators using MUVEs, ability is a natural area of interest. Student self-assessment can help explore the use and value of MUVEs in L2 teaching and learning. These learners saw ability as a quality mutually shared, facilitated, owned and employed by SL and various other SL users. Virtual subjectivity may actually be much more sophisticated than can be currently modeled, particularly in areas of both negative and positive ability and perceptions of ability.

Overall, previous studies of virtual subjectivity indicated that virtual subjectivity is multiple, and its flexible was based in appearance and in response to interaction. This study found that for adult learners appearance was not a major factor in generating desired or possible selves, but that interaction, in combination with personal reflection, was. Previous motivation studies indicated that L2 learners are adept at imagining possible selves, and that these might become self-guides if their visual imagination was richly detailed, and the tasks were realistic. This data is consonant with those studies. Clearly, the technical affordances of MUVE support rich visual detail. Many participants found tasks realistic. However, they were at times critical of the lack of tactile feedback (not currently available), and their expectations as $2 \mathrm{~L}$ learners may have led to disproportionate expectations when imagining themselves as a $3 \mathrm{~L}$ speaker.

\section{References}

Alvarez-Torres, M., Mishra, P., \& Zhao, Y. (2001). Judging a book by its cover: Cultural stereotyping of interactive media and its effect on the recall of text information. Journal of Educational Multimedia and Hypermedia, 10(2), 161-183. http://dx.doi.org/10.1016/j.paid.2010.05.037

Andreas, K., Tsiatsoa, T., Terzidou, T., \& Pomportsis, A. (2010). Fostering collaborative learning in Second Life: Metaphors and affordances. Computers and Education, 55(2010), 603-615. http://dx.doi.org/10.1016/j.compedu.2010.02.021

Anetta, L., Klesath, M., \& Holmes, S. (2008). V-learning: How gaming and avatars are engaging online students. Technology Review, 107(3), 50-55. Retrieved from http://innovateonline.info/pdf/vol4_issue3/V-Learning

Argamon, S., Bloom, K., Esuil, A., \& Sebastiani, F. (2007). Automatically determining attitude type and force for sentiment analysis. Proceedings of the 3rd language and technology conference (LTC '07), Poznan, PL, 369-373. http://dx.doi.org/10.1007/978-3-642-04235-5_19

Bailenson, J., Beall, A., Loomis, J., Blascovich, J., \& Turk, M. (2004). Transformed social interaction: Decoupling representation from behaviour and form in collaborative virtual environments. Presence, 13, 428-441. http://dx.doi.org/10.1111/j.1468-2958.2005.tb00881.x 
Blinka, L. (2008). The relationships of players to their avatars in MMORPGs: Differences between adolescents, emerging adults and adults. Cyberpsychology: Journal of Psychosocial Research on Cyberspace, 2(1), aricle 1. Retrieved from http://cyberpsychology.eu/view.php?cisloclanku=2008060901\&article=1

Bloor, T., \& Bloor, M. (2004). The functional analysis of English. Hodder Education, Great Britain.

Boyatzis, R. E., \& Akrivou, K. (2006). The ideal self as the driver of intentional change. Journal of Management Development, 25(7), 624-642. http://dx.doi.org/10.1108/02621710678454

Bruce, R., \& Wiebe, J. (1999). Recognizing subjectivity: A case study in manual tagging. Natural Language Engineering, 5(1), 1-16. $\quad$ Retrieved from $\mathrm{http} / / /$ citeseerx.ist.psu.edu/viewdoc/download?DOI=10.1.1.31.8785\&rep=rep1\&type=pdf

Cercone, K. (2003). Characteristics of adult learners with implications for online learning design. AACE Journal, 16(2), 137-159. Retrieved from http://ww.editlib.org/p/24286

Chae, S. W., \& Lee, K. C. (2009). Empirical Analysis of the Effect of Avatars on Learner's e-Learning Performance: Emphasis on Trust Transference between Avatars and Contents. Asia Pacific Journal of Information Systems, 19(4), 149-176. Retrieved from http://www.earticle.net/article.aspx?sn=115004

Chan, D. (2006). Negotiating Intra-Asian Games Networks: On Cultural Proximity, East Asian Games Design, and Chinese Farmers. Fibreculture 8 FCJ-049. Retrieved August 20, 2010, from http://www.journal.fibreculture.org/issue8/issue8_chan.html

Connor-Greene, P. (2000). Making connections: Evaluating the effectiveness of journal writing in enhancing student learning. Teaching of Psychology, 27(1), 44-46. http://dx.doi.org/10.1207/S15328023TOP2701_10

Crystal, D. (2003). English as a Global Language. Cambridge: Cambridge University Press. http://dx.doi.org/10.1017/CBO9780511486999

Cziser, K., \& Dörnyei, Z. (2005). The Internal Structure of Language Learning Motivation and Its Relationship with Language Choice and Learning Effort. The Modern Language Journal, 89(i), 19-36. http://dx.doi.org/10.1111/j.0026-7902.2005.00263.x

De Lucia, A., Francese, R., Passero, I., \& Tortora, G. (2009). Development and evaluation of a virtual campus on second life: The case of second DMI. Computers \& Education, 52(1), 220-233. http://dx.doi.org/10.1016/j.compedu.2008.08.001

DeCoursey, C. A. (2012). Trialing cartoons: Teachers' attitudes towards animation as an ELT instructional tool. Computers \& Education, 59(2), 436-448. http://dx.doi.org/10.1016/j.compedu.2011.09.005

Dörnyei, Z. (2005). The Psychology of the Language Learner: Individual Differences in Second Language Acquisition. New Jersey: Lawrence Erlbaum Associates. http://dx.doi.org/10.1017/S0272263105370288

Dörnyei, Z., \& Clement, R. (2001). The Psychology of the Language Learner: Individual Differences in Second Language Acquisition. New Jersey: Lawrence Erlbaum Associates. http://dx.doi.org/10.1017/S0272263101241059

Dörnyei, Z., \& Ushioda, E. (2009). Motivation, Identity and the L2 Self. Bristol, UK: Multilingual Matters.

Garrison, D., Anderson, T., \& Archer, W. (2000). Critical inquiry in a text-based environment: Computer conferencing in higher education. The Internet and Higher Education, 2(2-3), 87-105. http://dx.doi.org/10.1016/S1096-7516(00)00016-6

Halliday, M. (1985). Spoken and Written Language. Geelong, Victoria: Deakin University Press.

Halliday, M. A. K. (1994). An Introduction to Functional Grammar. London: Edward Arnold.

Herring, S. C., Scheidt, L. A., Wright, E., \& Bonus, S. (2005). Weblogs as a bridging genre. Information Technology \& People, 18(2), 142-171. http://dx.doi.org/10.1108/09593840510601513

Higgins, E. T. (1998). Promotion and Prevention: Regulatory focus as a motivational principle. Advances in Experimental Social Psychology, 1998(30), 1-46. http://dx.doi.org/10.1016/S0065-2601(08)60381-0

Holstein, J. A., \& Gulbrium, J. F. (2000). The Self We Live By: Narrative Identity in a Postmodern World. Oxford: Oxford University Press.

Horrocks, C. (2003). The End of Everything: Postmodernism and the Vanishing of the Human. Cambridge: Icon Books. 
Hoyle, R. H., \& Sherrill, M. (2006). Future orientation in the self-system: Possible selves, self-regulation and behaviour. Journal of Personality, 74(6), 1673-1696. http://dx.doi.org/10.1111/j.1467-6494.2006.00424.x

Hunston, S., \& Thompson, G. (Eds.). (2001). Evaluation in text: Authorial stance in the construction of discourse. Oxford: Oxford University Press.

Jin, S.-A. (2009). Avatars mirroring the actual self versus projecting the ideal self: The effects of self-priming on interactivity and immersion in an exergame, Wii Fit. Cyberpsychology and Behaviour, 12(6), 761-765. http://dx.doi.org/10.1089/cpb.2009.0130

Jin, S.-A., \& Park, N. (2009). Parasocial interaction with my avatar: Effects of interdependent self-construal and the mediating role of self-presence in an avatar-based console game, Wii. Cyberpsychology and Behavior, 12(6), 723-727. http://dx.doi.org/10.1089/cpb.2008.0289

Johnson, S., Suriya, C., Won Yoon, S., Berret, J., \& La Fleur, J. (2002). Team development and group processes of virtual learning teams. Computers \& Education, 39(2002), 379-393. http://dx.doi.org/10.1016/S0360-1315(02)00074-X

Jones. D. (2003). I, Avatar: Constructions of Self and Place in Second Life and the Technological Imagination. Gnovis, 6. Retrieved August 7, 2010, from http://gnovisjournal.org/files/Donald-E-Jones-I-Avatar.pdf

Majeski, R., \& Stover, M. (2007). Theoretically based pedagogical strategies leading to deep learning in asynchronous online gerontology courses. Educational Gerontology, 33(3), 171-185. http://dx.doi.org/10.1080/03601270600850826

Malvern, D., Richards, B., Chipere, N., \& Durám, P. (2004). Lexical diversity and language development: Quantification and assessment. New York: Palgrave MacMillan. http://dx.doi.org/10.1057/9780230511804

Mansfield, N. (2000). Subjectivity: Theories of the Self from Freud to Haraway. St. Leonard's N.S.W., Allen and Unwin.

Marín-Arrese, J. (2004). Evidential and epistemic qualifications in the discourse of fact and opinion: A comparable corpus study. In J. Marín-Arrese (Ed.), Perspectives on Evidentiality and Modality (pp. 153-184). Madrid: Editorial Complutense.

Markus, H. R., \& Nurius, P. (1986). Possible Selves. American Psychologist, 1986(41), 954-969. http://dx.doi.org/10.1037/0003-066X.41.9.954

Martin, J. R., \& Rose, D. (2003). Working with discourse: Meaning beyond the clause. UK: Continuum.

Martin, J. R., \& White, P. R. R. (2005). The Language of Evaluation: Appraisal in English. London UK: Palgrave Macmillan.

Meadows, M. (2008). I, avatar: The culture and consequences of having a Second Life. USA: New Riders Press.

Morrison, K. (1996). Developing reflective practice in higher degree students through a learning journal. Studies in Higher Education, 21(3), 317-332. http://dx.doi.org/10.1080/03075079612331381241

Norton, B. (2000). Gender, Ethnicity and Educational Change. London: Longmans.

O'Donnell, M. (2008). Demonstration of the UAM Corpus Tool for text and image annotation. Proceedings of the ACL-08: HLT Demo Session (Companion Volume) (pp. 13-16). Columbus, Ohio: Association for Computational Linguistics. Retrieved from http://aclweb.org/anthology/P/P08/P08-40.pdf

Panetta, C. (Ed.). (2001). Contrastive rhetoric revisited and refined. Mahwah NJ: Erlbaum.

Panther, K. U., \& Thornburg, L. (1999). The potentiality for actuality metonymy in English and Hungarian. In K. U. Panther, \& G. Raggen (Eds.), Metonymy in language and thought (pp. 333-357). Amsterdam: John Benjamins.

Polanyi, L., \& Zaenen, A. (2006). Computing attitude and affect in text: Theory and applications. USA: Springer. http://dx.doi.org/10.1007/1-4020-4102-0_1

Ruddell, R., \& Unrau, N. (2004). Theoretical models and processes of reading (5th ed.). Newark DE: International Reading Association. http://dx.doi.org/10.1598/0872075028

Ruvolo, A. P., \& Markus, H. R. (1992). Possible selves and performance: The power of self-relevant imagery. Social Cognition, 10(1), 95-124. http://dx.doi.org/10.1521/soco.1992.10.1.95

Sandrock, P. (2002). Creating Intrinsic Motivation to Learn World Languages. The Modern Language Journal, 86(4), 610-612. Retrieved from http://www.jstor.org/stable/1192732 
Scherer, K., Schorr, A., \& Johnstone, T. (Eds.). (2001). Appraisal processes in emotion: Theory, methods, research. Oxford: Oxford University Press.

Schultze, U., \& Leahy, M. (2009). The avatar-self relationship: Enacting Presence in Second Life. ICIS 2009 Proceedings. Paper 12. Retrieved May 11, 2012, from http://aisel.aisnet.org/icis2009/12

Schunk, D. H., \& Zimmerman, B. J. (Eds.). (2007). Motivation and Self-Regulated Learning: Theory, Research and Applications. New York: Lawrence Erlbaum.

Stack, G. J. (2012). The language of possibility and existential possibility. The Modern Schoolman, 50(2), 159-182. http://dx.doi.org/10.5840/schoolman19735026

Stevens, V. (2006). Second Life in Education and Language Learning. TESL-EJ, 10(3). Retrieved May 18, 2012, from http://tesl-ej.org/ej39/int.html

Subassic, P., \& Huettner, A. (2001). Affect analysis of text using fuzzy semantic typing. IEEE Transactions on Fuzzy Systems, 9(4), 483-496. http://dx.doi.org/10.1109/91.940962

Taboada, M., Brooke, J., Tofiloski, M., Voll, K., \& Stede, M. (2011). Lexicon-based methods for sentiment analysis. Computational Linguistics, 1(1), 1-42. http://dx.doi.org/10.1162/COLI_a_00049

Thompson, G. (2004). Introducing functional grammar. Great Britain: Hodder Education.

Tofts, D. (2003). Avatars of the tortoise: Life, longevity and simulation. Digital Creativity, 14(1), 54-63. http://dx.doi.org/10.1076/digc.14.1.54.8811

Ushioda, E. (2006). Language Motivation in a Reconfigured Europe: Access, Identity, Autonomy. Journal of Multilingual and Multicultural Development, 27(2), 148-161. http://dx.doi.org/10.1080/01434630608668545

Vasalou, A., Johnson, A., \& Pitt, J. (2007). Construing my online self: Avatars that increase self-focused attention. Proceedings of ACM CHI 2007 Conference on Human Factors in Computing Systems (pp. 445-448). ACM Press.

Veletsianos, G. (2010). Contextually relevant pedagogical agents: Visual appearance, stereotypes and first impressions and their impact on learning. Computers \& Education, 55(2010), 576-585. http://dx.doi.org/10.1016/j.compedu.2010.02.019

Veletsianos, G., \& Miller, C. (2008). Cognitive and affective benefits of an animated pedagogical agent: Considering contextual relevance and aesthetics. Journal of Educational Computing Research, 36(4), 372-377. http://dx.doi.org/10.2109/A064-U776-4208-N145

Wallace, P., \& Maryott, J. (2009). The Impact of Avatar Self-Representation on Collaboration in Virtual worlds. Journal of Online Communication, 5(5). Retrieved May 3, 2012, from $\mathrm{http}: / /$ www.innovateonline.info/index.php?view=article\&id=689

Wei, Y., \& Lei, L. (2011). Lexical Bundles in the Academic Writing of Advanced Chinese EFL Learners. RELC: A Journal of Language Teaching and Research, 42(2), 155-166. http://dx.doi.org/10.1177/0033688211407295

Whitelaw, C., Garg, N., \& Argamon, S. (2005). Using appraisal groups for sentiment analysis. Proceedings of the conference on information and knowledge management. ACM Press. http://dx.doi.org/10.1145/1099554.1099714

Wiebe, J., Wilson, T., \& Cardie, C. (2005). Annotating expressions of opinions and emotions in language. Language Resources and Evaluation, 39(2-3), 165-210. http://dx.doi.org/10.1007/s10579-005-7880-9

Wiebe, J., Wilson, T., Bruce, R., Bell, M., \& Martin, M. (2004). Learning subjective language. Computational Linguistics, 30(3), 277-308. http://dx.doi.org/10.1162/0891201041850885

Yashmina, T. (2002). Willingness to Communicate in a Second Language: The Japanese EFL Context. Modern Language Journal, 86(1), 54-66. http://dx.doi.org/10.1111/1540-4781.00136

Yee, N., \& Bailenson, J. N. (2009). The Proteus effect implications of transformed digital self-representations on online and offline behavior. Communication Research, 36(2), 265-312. http://dx.doi.org/10.1111/j.1468-2958.2007.00299.x 


\section{Copyrights}

Copyright for this article is retained by the author(s), with first publication rights granted to the journal.

This is an open-access article distributed under the terms and conditions of the Creative Commons Attribution license (http://creativecommons.org/licenses/by/3.0/). 